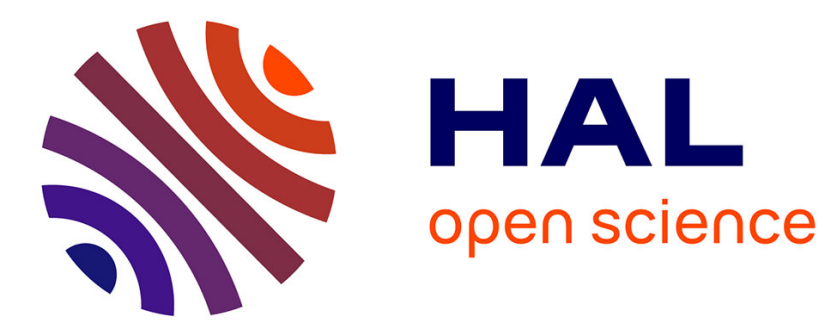

\title{
Hydrophilic and optical properties of nanostructured titania prepared by solgel dip coating
}

\author{
M C Ferrara, L Pilloni, S Mazzarelli, L Tapfer
}

\section{To cite this version:}

M C Ferrara, L Pilloni, S Mazzarelli, L Tapfer. Hydrophilic and optical properties of nanostructured titania prepared by solgel dip coating. Journal of Physics D: Applied Physics, 2010, 43 (9), pp.95301. 10.1088/0022-3727/43/9/095301 . hal-00629941

\section{HAL Id: hal-00629941 \\ https://hal.science/hal-00629941}

Submitted on 7 Oct 2011

HAL is a multi-disciplinary open access archive for the deposit and dissemination of scientific research documents, whether they are published or not. The documents may come from teaching and research institutions in France or abroad, or from public or private research centers.
L'archive ouverte pluridisciplinaire HAL, est destinée au dépôt et à la diffusion de documents scientifiques de niveau recherche, publiés ou non, émanant des établissements d'enseignement et de recherche français ou étrangers, des laboratoires publics ou privés. 


\title{
Hydrophilic and optical properties of nanostructured titania prepared by sol-gel dip coating
}

\author{
M.C. Ferrara ${ }^{*}$, L. Pilloni ${ }^{1}$ S. Mazzarelli and L. Tapfer \\ ENEA, Dept. of Advanced Phys. Technologies and New Materials (FIM), Brindisi Research \\ Centre, Strada Statale 7 Appia, 72100 Brindisi, Italy \\ ${ }^{1}$ ENEA, Dept. of Advanced Phys. Technologies and New Materials (FIM), CR Casaccia, Via \\ Anguillarese 301, 00060 S. M. di Galeria, Rome, Italy
}

(*) corresponding author: cristina.ferrara@enea.it 


\begin{abstract}
Nanostructured titania thin films were prepared under controlled atmospheric conditions by sol-gel dip-coating technique on glass, fused silica and (100)-silicon substrates. Two different sol-gel routes were employed by using different precursor solutions, a highly acid solution and a polymer-like solution. The influence of sol composition and of the substrate type on the morphology, coating porosity, surface roughness, crystalline phases and grain size of the titania films were investigated in detail. In addition, the relationship between microstructural/morphological properties and the optical properties (energy gap, refractive index and extinction coefficient) and the hydrophilic performance of the coatings were evaluated. Our experimental results clearly indicate that the sol composition and substrate type remarkably influence the films morphology and microstructure, moreover they consequently modify the optical response and hydrophilic performances of the samples, showing that superhydrophilic titania coatings can be obtained opportunely by choosing the composition of the precursors sol-gel solution. Blue shift of the band gap energy and a band structure mutation from indirect to direct were also revealed. The hydrophilic properties and the change of the band gaps transition can be attributed to oxygen vacancy on the surface of the titania nanocrystallites that gives rise to $\mathrm{Ti}^{3+}$ sites and, consequently, to structural changes/defects of the anatase nanoarchitecture. These findings allow us to design and tailor the optical and hydrophilic properties of the titania coatings.
\end{abstract}

PACS Numbers: $\quad$ 68.55. -a $\quad$ 81.20.Fw $\quad$ 81.07.Bc $\quad$ 78.66.w 


\section{Introduction}

$\mathrm{TiO}_{2}$-based films or powders are of great interest for optical, catalytic, photocatalytic and photovoltaic applications because of their electronic and optoelectronic properties and their high chemical, biological and structural stability [1-10]. In particular, the possibility of controlling the solar energy absorption, the photocatalytic activity and the surface hydrophilic performances of $\mathrm{TiO}_{2}$ coatings by tailoring their surface morphology, crystalline structure and the energy gap is an important aim to achieve, in particular for advanced device applications $[2,6,8,11-13]$.

One of the most attractive features of $\mathrm{TiO}_{2}$ anatase phase is its large optical band gap energy, about $3.2 \mathrm{eV}$, corresponding to an indirect band to band electronic transition $[2,10$, 14]. This should favour the use of anatase as wide band-gap semiconductor, specifically for the charge separation in dye-sensitized solar cell, because in indirect band gap materials less electron-hole recombination occurs [2]. The large energy band gap is however a limit for the photocatalytic efficiency of $\mathrm{TiO}_{2}$ under sunlight irradiation because only $2 \%-3 \%$ of the UV light of the total solar spectrum can be used for water splitting [2]. Therefore, much effort has been devoted to increase the photocatalytic efficiency of $\mathrm{TiO}_{2}$ by widening the wavelength range of photoactivation through the doping of metals, rare elements, nitrogen or iron, and the tailoring and optimizing of the morphology and microstructure in order to increase the surface area and the surface hydrophilicity $[2,5,6,10,15]$. The required surface area and hydrophilicity properties can be obtained by synthesizing titania anatase of small grain/particles size. In fact, by reducing the particle size, the surface area of $\mathrm{TiO}_{2}$ increases leading to a more efficient light and water absorption and consequently to a higher photoefficiency and photocatalytic activity $[5,6]$. Alternatively, a temporary superhydrophilic 
state (water contact angle $<10 \%$ ) of titania can be obtained by exposition to ultraviolet light. $[6,7,16,17]$.

The aim of our work is to fabricate nanostructured titania anatase coatings by employing two different sol-gel routes and to investigate the correlation among the optical properties (energy gap, refractive index and extinction coefficient), the hydrophilic performances of titania and the microstructure and morphology of the coatings. The titania thin films were prepared by two different acid catalyzed sol-gel titania precursor solutions. In fact, a characteristic of the sol-gel synthesis is that a potential control of the microstructure and the morphology of materials can be achieved by opportunely choosing the composition of the sol-gel solution and the thermal curing parameters [18-20]. However, also at fixed process parameters, substrate properties, such as composition, topography, phase and orientation, can affect the surface roughness, morphology and microstructure of the coating [23-27]. Therefore, we have investigated the influence of some common substrates, crystalline (Si100) and amorphous (soda-lime glass, fused silica) substrates, on the titania growth by using a sol-gel dip coating technique. The dependence of optical properties and hydrophilic performances on microstructuctural/morphological properties was investigated in detail. The film thickness, surface and interface roughness, mass density (or refraction index), size and phase of the crystalline domains were evaluated by glancing-incidence X-ray diffraction (GIXRD) and X-ray reflectivity (XRR) measurements. The surface morphology, films porosity and grain sizes were evaluated by field emission scanning electron microscopy (FESEM). The optical properties were evaluated from reflectance and transmittance spectrophotometric data, while the hydrophilic performances measuring the water contact angle on the films surface. 


\section{Experimental Details: Sol-Gel synthesis and characterisation techniques}

\subsection{Sol-Gel synthesis}

Two titania precursors sols, a $\mathrm{TiO}_{2}$-nanoparticles bath (Sol-1) [28] and a polymer-like precursors solution (Sol-2) were prepared using titanium-isopropoxide (TIP) as alkoxide precursor of titanium (Ti), isopropanol (IPA) as solvent, $\mathrm{H}_{2} \mathrm{O}$ for the hydrolysis and $\mathrm{HCl}$ as acid catalyst of the hydrolysis/condensation reaction of the alkoxide groups. Acetylacetone, AcAc, was employed in the polymeric-like titania solution as chelating agent of the titaniumalkoxide. The solution compositions were a molar ratio of TIP/IPA=0.04, $\mathrm{TIP} / \mathrm{H}_{2} \mathrm{O}=0.65$, $\mathrm{TIP} / \mathrm{HCl}=0.84$ for $\mathrm{Sol}-1$, and TIP/IPA=0.04, TIP/ $\mathrm{H}_{2} \mathrm{O}=0.4, \mathrm{TIP} / \mathrm{HCl}=11$, TIP/AcAc=2 for Sol-2. The films were deposited under controlled temperature and atmospheric conditions (about $20^{\circ} \mathrm{C}$ and $31 \%$ relative humidity) by dip-coating techniques on (100)-Si wafer (samples A1, A2), fused silica (samples B1, B2), and soda lime glass (samples C1, C2). In the text we label the samples obtained by Sol-1 by A1, B1, C1, whereas A2, B2 and C2 refer to the samples obtained by Sol-2. The resulting gel coatings were first dried at $110^{\circ} \mathrm{C}$ for 20 minutes and then densified by means of a thermal treatment in air at $500^{\circ} \mathrm{C}$ for 1,5 hours.

\subsection{Characterisation techniques}

The GIXRD and XRR experiments were carried out by using an X-ray diffractometer in parallel beam geometry (Philips MPD PW1880) optimized for small-angle scattering measurements. For all the measurements $\mathrm{CuK} \alpha$-radiation $\left(\lambda_{\mathrm{CuK \alpha}}=0.154186 \mathrm{~nm}\right)$ was 
employed. The GIXRD measurements were performed by keeping the incident angle $\omega_{\mathrm{i}}$ (angle between incident beam and sample surface) fixed at $0.5^{\circ}$ while recording the scattered $\mathrm{X}$-ray beam by moving the detector along the goniometer circle in the $2 \theta$ range between $10^{\circ}$ and $100^{\circ}$. Within the XRR regime, we took two types of scans: i) specular $(\omega, 2 \theta)$ scans in which the grazing angle of incidence of the x-rays is equal to the exit angle; ii) transverse $\omega$ scans (diffuse scattering) in which the exit angle was fixed. The $(\omega, 2 \theta)$ scans were performed in the $2 \theta$ range between $0^{\circ}$ and $6^{\circ}$ with a step size of $0.02^{\circ}$.

The morphology, the grains size and the porosity of the samples were analysed by a FE-SEM LEO 1530, equipped with a high-resolution in-lens secondary electron detector. The FE-SEM images were recorded at different electron accelerating voltages in the range between $3 \mathrm{keV}$ and $20 \mathrm{keV}$. The resolution limit of our FE-SEM is $1.2 \mathrm{~nm}$ at $20 \mathrm{keV}$ and $3 \mathrm{~nm}$ at $1 \mathrm{keV}$. The porosity and the grains size were measured on the digitalized images using the public domain software NIH-IMAGE [29] running on a Macintosh computer.

The energy gap and the optical parameters of the films grown on silica and soda lime glass substrates were evaluated by analysing the spectrophotometric measurements of the transmittance $T(\lambda)$ and reflectance $R(\lambda)$, which were carried out at near normal incidence in the spectral range $300-1500 \mathrm{~nm}$ by using a VARIAN Cary 5 spectrophotometer. The curves of the refractive index and the extinction coefficient were determined by processing the experimental $T(\lambda)$ and $R(\lambda)$ curves with a home-made software program for the determination of refractive index and extinction coefficient [30].

The water contact angle (CA) on the films and nude substrates surface was measured by means of a 100 NRL Contact Angle Goniometer (Rame- Hart, Inc.), by placing a drop of water on the uppermost surface and measuring the angle between the horizontal plane and the tangent to the drop at the point of contact with the surface. 


\section{Results and discussion}

\section{$\mathrm{X}$-ray diffraction and $\mathrm{X}$-ray reflectivity analysis}

The experimental GIXRD patterns acquired from the samples obtained by using the nanoparticulates bath as titania precursor solution are shown in Fig.1. The GIXRD pattern in Fig.1 refers to the film A1 grown on (100)-Si substrate (a) and exhibits the Bragg peaks of the $\mathrm{TiO}_{2}$ tetragonal phase in the anatase structural modification (ICDD card \# 71-1169 SG

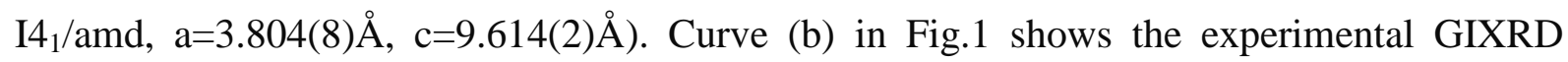
pattern of the film B1 grown on the silica substrate. Here, in addition to the Bragg peaks of the titania anatase phase, a broad peak, located at $2 \theta \approx 21^{\circ}$, from the amorphous substrate is also observed. Curve (c) shows the experimental GIXRD spectrum of the film $\mathrm{C} 1$ grown on the glass substrate. Also here, the broad peak from the amorphous substrate $\left(2 \theta \approx 23^{\circ}\right)$ is well pronounced and is superposed on the weaker Bragg peaks of the anatase phase. For all the samples, the intensities of the several reflections indicate a random orientation of the crystalline domains and from a qualitative analysis of the shape of the peaks, we deduce that the $\mathrm{TiO}_{2}$ particles are of nanometric size.

The average diffracting domains of the $\mathrm{TiO}_{2}$ grains was estimated from the broadening of the diffraction peaks applying the Scherrer formula: [31],

$D=0.94 \lambda /\left(\Delta \omega \cos \theta_{B}\right)$ 
where $D$ is the average crystallite size (in the direction of momentum transfer), $\lambda$ is the $\mathrm{X}$-ray wavelength , $\Delta \omega$ is the calculated FWHM of the diffraction peak in radians and $\theta_{\mathrm{B}}$ is the Bragg angle.

In order to investigate the microstructure of the thin films and to quantitatively ascertain the differences among the several samples, we performed the quantitative analysis of the x-ray spectra by means of pattern decomposition method [32, 33]. The corresponding Williamson-Hall plots showed that the X-ray line broadening was essentially isotropic and that the least-squares line through the points had a positive slope and a non-zero intercept [33]. This indicates that diffracting domains are isotropic in the shape and there is also a microstrain contribution. However, the size-strain parameters were definitely calculated by considering an "average size-strain plot" [34], which gives a better estimation in cases of isotropic line broadening and has the advantage that less weight is given to data from reflections at high angles, where the precision is usually lower. The RMS strain is in the range between $7 * 10^{-4}$ (sample A1) and $2.0 * 10^{-3}$ (sample B1 and C1).

The experimental GIXRD patterns of the titanium oxide films generated from the polymer sol (Sol-2) on the single-crystal (100)-Si and on the amorphous silica and glass substrates, are reported in Fig.2. The diffraction patterns obtained are very similar to the results shown in Fig.1, except for the film deposited on the glass substrate (curve (c) of sample $\mathrm{C} 2$ in Fig.2) that does not exhibit Bragg peaks of the titanium oxide films indicating that the film $\mathrm{C} 2$ has an amorphous structure. The average crystalline domain size $\langle D\rangle$ was found to be $3.3 \pm 1 \mathrm{~nm}$ and $4.6 \pm 1 \mathrm{~nm}$ for the A2 and B2 films, respectively.

X-ray specular reflectivity (XSR) and transverse scan (X-ray diffuse scattering, XDS) measurements were performed in order to characterize the morphological properties of the titanium oxide films deposited. In particular, the mass density (chemical composition) of the 
deposited films was determined from the angular position of the Yoneda wings in the XDS patterns, and the thickness and the surface roughness were determined by simulation of the experimental XSR patterns [35]. The patterns of all the samples exhibit well defined Kiessig fringes due to the X-ray wave interference that occurs between the waves scattered by the film/substrate interface and the film surface. This observation indicates a good structural order and a morphological uniformity within the film thickness and along the film surface.

Figure 3 shows the experimental XSR pattern and three transverse scans recorded at different $2 \theta$ detector angular positions $\left(2 \theta=1.4^{\circ},=2.0^{\circ}\right.$ and $=3.0^{\circ}$, respectively $)$ on the titanium oxide film, generated from the polymer sol and deposited on $\mathrm{Si}(100)$ substrate (sample A2). The Kiessig interference fringes in the XSR pattern and the Yoneda wings in the XDS patterns are well pronounced. The two Yoneda peaks appear at the critical angle $\theta_{\mathrm{c}}$ of incident and exit X-ray beam, respectively. Hence, the determination of the critical angle through the angular position of the Yoneda peaks allows us to determine the mass density (or the real part of the dielectric susceptibility) of the deposited titanium oxide films. The mass density is related to the critical angle $\theta_{c}$ by the equation $[33,35]$ :

$\rho_{m}=\frac{\pi \cdot \theta_{c}^{2}}{r_{e} \cdot \lambda^{2} \cdot N_{A}} \cdot \frac{\sum_{i}\left(Z_{i}+f_{i}^{\prime}\right)}{\sum_{i} M_{i}}$

where $r_{e}$ is the classical electron radius, $\lambda$ is the X-ray wavelength used, $N_{A}$ is the Avogadro's number, and $Z_{i}, f^{\prime}{ }_{i}$ and $M_{i}$ are the nuclear charges, the dispersion corrections and the atomic weights of the $i$-th chemical element, respectively.

The experimental XSR patterns were simulated by using the Parratt's recursive equations, considering the mass density values obtained from the Yoneda peak position 
analysis, and by using the Nevot-Croce factor to describe the interface and surface roughness of the thin surface films [35]. Figure 4 shows the experimental and simulated XSR patterns of sample A2 (see Fig.3). The slope (decay) of the reflected intensity above the critical angle $\theta \mathrm{c}$ is related to the interface and surface roughness in accordance with the Nevot-Croce model. The inset of Fig.4 shows the enlargement of a part of the XSR patterns with the well resolved Kiessig fringes. The interference frequency is related to the layer thickness of the deposited film. The excellent agreement between the experimental and simulated pattern of the intensity modulation and fringe spacing should be noticed.

The structural (crystallites size, film thickness), morphological (surface roughness) and compositional (mass density) parameters as obtained from the GIXRD, XSR and XDS measurements on all the analyzed samples are summarised in Table I.

The X-Ray diffraction analysis shows that the samples are characterised by low values of the crystalline domain dimension: from 11 to $14 \mathrm{~nm}$ for the samples obtained by Sol-1 and less than $5 \mathrm{~nm}$ for the samples obtained by the polymer type sol (Sol-2). Moreover, among the films grown by using the same sol but on different substrates, a noticeable difference in the average crystallite diameter and the density was found. The reason for this behaviour could be the substrate surface topography and chemistry, and the diffusion of impurities from the substrate into the film [22-26]. Very likely, the high flatness of silica and (100) Si substrates enhances the $\mathrm{TiO}_{2}$ crystallization [23, 24] favouring a larger average crystallite diameter and a good uniformity in thickness. Moreover, it is presumed that, as the mass density values suggest, Si-(100) crystalline substrate favours the formation of titania films with higher closepacked structure. On soda lime glass, the surface roughness and the diffusion of various species, mainly $\mathrm{Na}[23,24]$, into the film inhibit the crystallization by causing a minor size of the $\mathrm{TiO}_{2}$ crystallites. This is particular evident in the samples $\mathrm{C} 2$ grown by using the polymer 
sol. For this sample, the presence of alkaline species has repressed the growth of the $\mathrm{TiO}_{2}$ crystallites, determining only an initial stage of the crystallization process of the film. In the case of the sample $\mathrm{C} 1$, grown from a $\mathrm{TiO}_{2}$ nano-particulate solution, the presence of the impurities may have caused the loose packing of the crystallites and also favoured the rather rough interfaces of the film.

The samples synthesized by using the polymer-like precursors (Sol-2) exhibit not only a smaller crystallites size $(<5 \mathrm{~nm})$ and a slightly higher surface roughness $(\sim 1.3 \mathrm{~nm})$, but also a much lower mass density with respect to the samples prepared by using the highly acid precursor solution Sol-1. Here, the experimentally determined mass density is about $30 \%$ lower than the theoretical value of anatase titania $\left(4.26 \mathrm{~g} / \mathrm{cm}^{3}\right)$. The reduced mass density of the coatings can be explained by considering a film porosity that is very much pronounced in samples prepared by using Sol-2. This finding is also corroborated by FE-SEM experiments that will be reported and discussed in the following.

\section{Surface morphology of the titania coatings}

FE-SEM images of the top surface of the samples were performed on different surface areas $\left(\sim 1 \mu n^{2}\right.$ each) of the films. An almost regular and homogeneous surface morphology for all the deposited titania films was found. Figures 5 and 6 show the SEM images representative of samples grown by using Sol-1 and Sol-2 as precursor solutions, respectively. The mean grains diameter $G$ and mean pores sizes $D_{P}$ as measured on the digitalized images of the $\mathrm{TiO}_{2}$ films are reported in Table 2. The SEM analysis carried out on the samples under examination reveals a granular structure. In particular, the SEM results of the samples A1, B1 and C1 
demonstrate that they have about $11 \mathrm{~nm}$ sized grains. Nevertheless, the samples A1 and B1 show a different superficial porosity with respect to sample $\mathrm{C}$, which exhibits a larger porosity. In particular, the data show a mean diameter value of the surface pores of about 2 $\mathrm{nm}$ for the samples $\mathrm{A} 1$ and $\mathrm{B} 1$, and $4 \mathrm{~nm}$ for the sample $\mathrm{C} 1$, respectively. If we compare the mean grain size with the mean crystalline domains size obtained from the X-ray diffraction measurements, we note a very good agreement. Consequently, we can conclude that the grains observed by SEM are made of single nanocrystallites of $\mathrm{TiO}_{2}$, and we can exclude the formation of aggregate forms (clustering).

The FE-SEM observations carried out on the samples A2 and B2 reveal that the two samples have a similar surface morphology with grains of size $G \approx 16 \mathrm{~nm}$ and a mean pore size $D_{P}$ of about $7 \mathrm{~nm}$. If we compare the mean grain size with the corresponding mean nanocrystalline domain dimension evaluated from the X-ray diffraction measurements, we note that the average grain diameters are larger than crystalline domains, showing therefore the formation of crystalline aggregates forms. The SEM observations performed on the sample C2 show that its amorphous structure is made up of grains of about $22 \mathrm{~nm}$ mean diameters and lower number of pores that are larger with respect to the other samples. The enhanced porosity for all the Sol-2 samples is in very good agreement with the much lower mass density for these coatings with respect to the Sol-1 samples as measured by XSR and XDS

The evidence that samples prepared by following the Sol-1 synthesis procedure did not show any formation of aggregates, while the Sol-2 synthesis leads to the formation of crystalline aggregates, is certainly correlated to the different chemical synthesis of the titania precursor sols. In fact, the Sol-2 procedure uses a polymer like precursor solution that due to the polymer-like structure may favour the formation of molecular domains (micelle-like) and, 
consequently, may promote the formation of agglomerates giving rise to polycrystalline particles.

\section{Hydrophilicity of the films}

The values of the surface-water contact angles, CA, measured both on the surface of the nude substrates and of the as-sintered titania films are summarized in Table 2. The reported values show that the samples generated by using the precursor Sol-2 are characterized by low values of the surface-water contact angle, below $7^{\circ}$, both on films grown on hydrophobic (100)-Si substrates, and on hydrophilic silica and glass substrates. Conversely, the coatings obtained by Sol-1 exhibit high water contact angles: about $30^{\circ}$ for the samples grown on silicon and silica substrates, and $55^{\circ}$ for the sample $\mathrm{C} 1$ deposited on glass. These findings show that highly hydrophilic titania coatings can be obtained by using Sol-2 both on hydrophobic and hydrophilic substrates, whereas more hydrophobic titania coatings are grown by using Sol-1. Moreover, the values of the contact angles suggest that titania hydrophilic properties are influenced both by interfacial tensions according to Young's equation and other phenomena, such as substrate surface roughness, porosity, and grain size dimension. In fact, from Table 2 we can see that samples with similar values of the grain sizes exhibit similar contact angles except for the case of the sample $\mathrm{C} 1$. This finding may be related to the high surface roughness of the samples $\mathrm{C} 1$. The low contact angles of the samples obtained from Sol-2 indicates that the water surface tension is much reduced. The contact angle of the samples A2, B2 and C2 were re-measured after few days of exposure to atmosphere finding $\mathrm{CA}$ values of about $13^{\circ}$. The $\mathrm{CA}$ results show that superhydrophilic titania layers $\left(\mathrm{CA}<10^{\circ}\right)$ can be obtained without doping or exposing to ultraviolet light. 
Moreover, because the UV-induced photocatalytic properties of $\mathrm{TiO}_{2}$ are associated with film hydrophilicity $[3,16]$, one can deduce that photocatalytic activity is favored in samples grown from Sol-2-like precursor solutions.

\section{Optical properties}

The experimental data of the real part of the complex refractive index of the $\mathrm{TiO}_{2}$ films grown on silica and soda lime substrates are shown in Fig.7, evaluating the coatings thickness values by means of XSR. As no calculated thickness was available for the sample $\mathrm{C} 1$, the film thickness value $(110 \pm 7) \mathrm{nm}$ was derived from the image of a cross-section slice obtained by fracturing the sample after a scratch on its surface with a Vidia pen.

The optical band gap energy was determined by means of the coating extinction coefficient $k$. To that purpose, for large band materials in a small energy range in the vicinity of the optical band gap energy $E_{g}$, the absorption coefficient $\alpha$ is assumed to follow the well known_dependence:

$\alpha h v \approx A\left(h v-E_{g}\right)^{r}$,

where $A$ is a sample-dependent constant parameter, $r$ is a constant equal to $1 / 2$ and 2 for direct and indirect allowed transitions, respectively, and $h v$ is the photon energy. Then, $E_{g}$ can be graphically estimated by a linear fit of the high-energy tail of $(\alpha h v)^{1 / r}[14,20]$. The absorption coefficient was then evaluated from the coating extinction coefficient $k$, as $\alpha=4 \pi k / \lambda$, where $\lambda$ is the wavelength. In literature, both direct and indirect band-to-band 
transitions of nano-crystalline anatase titania are reported $[14,36]$. Then, to establish the type of electronic transition of the coatings, the absorption coefficient data were fitted to the equation for both indirect and direct band gap transitions. The graphically estimated band gap values are reported in Table 2.

Figure 8 shows the $(\alpha h v)^{1 / 2}$ plots versus the photon energy $h v$ for an indirect transition, while Fig.9 shows the $(\alpha h v)^{2}$ plots for a direct transition. For the sake of clarity, only a small portion of the energy range around the optical band gap is displayed in the figures.

The dispersions of $(\alpha h v)^{1 / 2}$ of the samples under examination do not show an asymptotic linear behavior in the near-UV region (Fig.8). This finding suggests that contrary to bulk anatase, $\mathrm{TiO}_{2}$ nanoparticles with crystalline domain size minor than $14 \mathrm{~nm}$ do not exhibit an indirect type of band to band transition.

In Fig.9 the dispersions of $(\alpha h v)^{2}$ clearly show an asymptotic linear behavior in the near-UV region, and the intercepts of the linear-fit extrapolations with the horizontal axes led us to estimate the energy of the optical band gap corresponding to the direct electronic transition with the values of $3.78 \pm 0.01 \mathrm{eV}, 3.90 \pm 0.01 \mathrm{eV}, 3.93 \pm 0.01 \mathrm{eV}$ and $4.13 \pm 0.01 \mathrm{eV}$ for the samples B1, C1, B2 and C2 respectively. The found band gap values are higher than that of bulk anatase $\mathrm{TiO}_{2}, \mathrm{E}_{\mathrm{g}}$ (bulk) $=3.2 \mathrm{eV}$ and decrease with crystalline domain size of titania.

The results clearly indicate that the optical properties of the $\mathrm{TiO}_{2}$ coatings depend on the precursor solution, composition and substrate type. It is noteworthy that the refractive index plots reported in Fig.7 show that the optical properties of the $\mathrm{TiO}_{2}$ coatings vary with the solution composition and substrate type. In particular, the coatings obtained by using Sol-1 exhibit values of the refractive index which are higher than those generated by using Sol-2. 
Since the refractive index is determined by composition, morphology and structure, it is expected that for a range of samples of similar coating chemistry and structure, differences in effective refractive index between samples can mainly be related to differences in grain packing and, hence, to void fraction. Therefore, for the samples under examination, the higher refractive index of the samples grown by using Sol-1 can be attributed, in agreement with XSR results, to a higher packing density of the samples $\mathrm{A} 1, \mathrm{~B} 1$ and $\mathrm{C} 1$, with respect to the samples A2, B2 and C2. This finding is very likely related to the presence of organic chelating agent in Sol-2. In fact, the burnout of these organic residues during the sintering process causes the formation of pores inside the coatings, which yields a more porous structure and, consequently, leads to a lower refractive index.

The high values of the anatase titania energy gap (from 3.78 to $4.13 \mathrm{eV}$ ) are attributable to the well-known close relationship between the band gap energy and the crystallites size [37]. The appearance of quantum confinement effect in small sized nanocrystalline titania, resulting in a blue shift of the band gap and the absorption edge, has been already observed and envisaged by other authors in order to explain experimental findings similar to the ones described here $[14,36,38]$. In fact, these values are in accordance with values reported in recent works: for example a direct optical absorption gap of $3.8 \mathrm{eV}$ was observed for anatase nanoparticle films with particle diameter in the range of $10-15 \mathrm{~nm}[39,40]$; and values of $4 \mathrm{eV}$ and above were found for anatase nanoparticles in the diameter range between $1 \mathrm{~nm}$ and $2 \mathrm{~nm}$ [38]. However, the results and conclusions of other works suggest that quantum size effect in anatase nanoparticles would occur only for particle with diameter smaller than $2 \mathrm{~nm}[41,42]$. Currently, the electronic properties and the dependence of the band gap of anatase titania on the particle size is still a hot topic of intensive investigations and several aspects have to be clarified yet. 
The small size of the $\mathrm{TiO}_{2}$ crystallites of the samples prepared in this work has, very likely, an important role for the relived band structure mutation from indirect to direct too. Modifications of the band to band electronic transition have in fact been observed on studying materials that are constituted of small nano-sized crystallites and have been associated to structural changes of their surface [21, 43-45]. As for silicon based materials, the broadening of the energy gap and the conversion of the energy band structures from indirect to direct is widely reported in literature [43-45]. In particular, studies on the electronic band structures of hydrogen-terminated silicon nanowires have shown that quantum effect, crystallographic direction, strain and surface termination affect the energy band gap structure. Indeed, theoretical studies have shown that structural and electronic properties of anatase $\mathrm{TiO}_{2}$ nanocrystals depend on the surface facet configuration (crystallography) [46] and surface coverage (chemistry) [47]. In the same manner, the presence of chemical/structural defects on the crystallites surface of the samples under examination could explain both the changes of anatase band gap transition and the high hydrophily of the samples grown by Sol-2 characterised by very low diameters of crystallites and high porosity. In fact, as reported in different studies, the titania hydrophilic properties are attributed to the presence of $\mathrm{Ti}^{3+}$ sites and, consequently, to the oxygen vacancies that favour the occurrence of $\mathrm{OH}$ groups, which are in turn responsible for surface hydrophilicity [16, 48]. This is in agreement with the results of a very recent study that revealed the presence of structural changes of the uppermost surface of hydrophilic titania nanosheet after UV light irradiation [49].

$\mathrm{Ab}$ initio, density-functional investigations have shown that the anatase $\mathrm{TiO}_{2}$ crystals are delimited by crystallographic facets corresponding to (101) and (001) surfaces (equilibrium shape) [50]. The (101) surface is the most stable surface, and hence, the anatase crystal surface exposed to the air is constituted by more than $94 \%$ of (101) surfaces [50]. 
Therefore, it is reasonable to suppose that the hydrophilic properties can be ascribed to oxygen vacancy at the (101) surface of the titania grains resulting in the conversion of relevant $\mathrm{Ti}^{4+}$ sites to $\mathrm{Ti}^{3+}$ sites which are favourable for dissociative water adsorption $[16,48]$. This causes surface structural changes/defects of anatase nanoarchitecture [51], which in small sized nanocrystallites lead also mutation of the band gap transition from indirect to direct. Moreover, it is reasonable to suppose that by increasing the number of $\mathrm{Ti}^{3+}$ sites the wettability increases. This can explain the high hydrophilicity of the samples grown by Sol-2 characterised by high porosity, high surface area and, consequently, high number of (101) surfaces having $\mathrm{Ti}^{3+}$ sites exposed to the air.

\section{Conclusions}

We reported on the controlled synthesis of nanocrystalline titania thin films by using two different sol-gel routes, i.e. different acid catalyzed sol-gel titania precursor solutions, via the dip-coating technique. The coatings were deposited on different substrates: (100)-Si wafer, fused silica and glass. The influence of the two sol-gel titania precursor solutions, a polymer titania sol and a $\mathrm{TiO}_{2}$ nanoparticles bath, on the morphological, microstructural, optical and hydrophilic properties of $\mathrm{TiO}_{2}$ films was investigated in detail.

We found a remarkable influence of the sol composition and the substrate type on the structural, morphological, and hydrophilic properties of the coating properties. The experimental results have shown that the films prepared from the polymer sol have the lowest mass density (about $70 \%$ of the theoretical bulk value of anatase), and exhibit high hydrophilic properties. Conversely, the layers grown by the nano-particulate sol have a much 
higher mass density (about 90-96\% of the theoretical value), refractive index and contact angles. This suggests that the sol composition plays a crucial role in the determination of the microstructural/morphological properties of the titanium dioxide, so that highly hydrophilic titania coatings can be obtained without UV irradiation or doping. This finding is a very important and interesting result for catalytic applications where a high capability of holding adsorbed water is preferable.

The optical results have shown that all the prepared samples are characterised by high values of the energy gap (between 3.78 and $4.13 \mathrm{eV}$ ) caused by the quantum size effect that is induced by the small $\mathrm{TiO}_{2}$ crystallite size (less than $14 \mathrm{~nm}$ in diameter). Moreover, band structure mutations from indirect to direct have been shown too. The changes of the band gap and the hydrophilic properties can be imputable to small size of the crystalline domain size and presence of oxygen vacancy on the surface of the titania grains that gives rise to $\mathrm{Ti}^{3+}$ sites and, consequently, to structural changes/defects of anatase nanoarchitecture.

Our results demonstrate that the optical and hydrophilic properties of nanocrystalline titania can be tailored opportunely tuning the size dimension of the crystalline domain according to the specific coating applications.

\section{Acknowledgements}

This work is supported by the Regione Puglia (Bari, Italy) - Project HICOGI (PS_074). 


\section{References}

1. Mills Andrew; Le Hunte Stephen, (1997) Journal of Photochemistry and Photobiology A: Chemistry 108, 1

2. S. Banerjee, J. G. Gopal, P. Muraleedharan, A. K. Tyagi and B. Raj, (2006) Current Science 90, 1378

3. M. A. Caravaca, R. A. Casali, and J. C. Miño, (2009) Phys. Status Solidi B 246, 3

4. $\quad$ www.titaniumart.com/photocatalysis-ti02.html

5. D. Chen, F. Huang, Yi-B. Cheng and R. A. Caruso, (2009) Adv. Mater. 21, 2206

6. M. S. Nahara, K. Hasegawa, and S. Kagaya, (2006) Chemosphere 65, 1976

7. I. P. Parkin and R. G. Palgrave, (2005) J. Mater. Chem. 15, 1689

8. T. Hanley, Y. Krisnaudi, A. Eldewik, V. Luca and R. Howe, (2001) Ionic 7, 319

9. D Dzibrou, AM Grishin1, H Kawasaki1, (2008) Thin Solid Films 516, 8697

10. X.-G. Hou, A.-D. Liu, M.-D. Huang, B. Liao and X.-L. Wu, (2009) Chin. Phys. Lett. 26, 077106

11. D. Lee and M. Choi, (2000) J. Aerosol Science 31, Suppl. 1, 632

12. D. J. Kim, H. Hahn, S. H. Oh and E. J. Kim, (2002) Mat. Lett. 57, 355

13. K. Eufinger, D. Poelman, H. Poelman, R. De Gryse and G. B. Marin, (2007) J. Phys. D Appl. Phys. 40, 5232

14. K.M. Reddy, S. V. Manorama and A. R. Reddy, (2002) Mat. Chem. Phys. 78, 239

15. D. Luca, D. Mardare, F. Iacomi, and C. M. Teodorescu, (2006) Appl. Surf. Sci. 252, 6122

16. M. Langlet, S. Permpoon, D. Riassetto, G. Berthomé, E. Pernot, and J. C. Joud, (2006) J. Photochem. Photobiol. A 181, 203 
17. M. Miyauchi, A. Nakajima, T. Watanabe, and K. Hashimoto, (2002) Chem. Mater. 14,2812

18. Y. Gao and S.A. Elder, (2000) Mat. Lett. 44, 228

19. S. D. Burnside, V. Shklover, C. Barbè, P. Comte, F. Arendse, K. Brooks and M. Gratzel, (1998) Chem. Mater. 10, 2419

20. M C Ferrara, D Altamura, M Schioppa, L Tapfer, E Nichelatti, L Pilloni and M Montecchi， (2008) J. Phys. D: Appl. Phys. 41, 225408

21. V. Resta, A. M. Laera, M. C. Ferrara, E. Piscopiello, S. Mazzarelli, A. Mevoli, and L. Tapfer, (2009) Mater. Res. Soc. Symp. Proc. 1121, 14

22. Y. Zhao, C. Li, X. L, F. Gu, H. Jiang, W. Shao, L. Zhang and Y. He, (2007) Mat. Lett. 61, 979

23. M. Gartner, C. Parlog and P. Osiceanu, (1993) Thin Solid Films 234, 561

24. C. Parlog, M. Gartner, P.Osiceanu, A. Ianculescu, V. Teodorescu and F. Moise, (1996) Ceramics International 22, 95

25. V. Janicki and H. Zorc, (2004) SPIE 5250, 646

26. I. Van Driessche, G. Penneman, J.S. Abell, E. Bruneel and S. Hoste, (2003) Mat. Sci. Forum 426, 3517

27. J. Sancho-Parramon, J. Ferré-Borrull, S. Bosch, and M. C. Ferrara, (2003) Appl. Optics 42, 1325

28. P.W. Oliveira, H. Krug, A. Frantzen, M. Menning and H. Schmidt, (1997) SPIE 3136, 452

29. NIH Image by W. Rasbad (National Institute of HEALT, U.S.), http://rsb.info.nih.gov/nih-image/

30. L. De Caro and M.C. Ferrara, (1999) Thin Solid Films 342, 153 
31. A. Guinier, (1996) X-Ray Diffraction: In Crystals, Imperfect Crystals, and Amorphous Bodies (New York: Dover Publications)

32. J.I. Langford, (1999) The use of pattern decomposition or simulation to study microstructure: theoretical consideration, in X-ray Powder Diffraction Analysis of Real Structure of Materials, eds. R.L. Snyder, J. Fiala and H.-J. Bunge - (Oxford: IUCr/Oxford University Press), 59-81

33. M. Birkholz, (2006) Thin Film Analysis by X-ray Scattering (Weinheim: Wiley$\mathrm{VCH})$.

34. J.I. Langford (1992). The use of the Voigt function in determining microstructural properties from diffraction data by means of pattern decomposition, in Accuracy in Powder Diffraction: NIST Spec. Publ. 846 eds. E. Prince and J. K. Stalick (Washington DC: National Institute of Standards and Technology), 110-126.

35. J. Daillant and A. Gibaud, (1999) X-Ray and Neutron Reflectivity: Principles and Applications (Berlin: Springer Verlag)

36. G.-L. Tian, H.-B. He and J.-D. Shao, (2005) Chin. Phys. Lett. 22, 1787

37. L. E. Brus, (1984) J. Chem. Phys. 80, 4403.

38. N. Satoh and K. Yamamoto, (2009) Synthetic Metals 159, 813

39. Y. Gao, Y. Masuda, Z. Peng, T. Yonesaa and K. Koumoto, (2003) J. Mater. Chem. 13, 608

40. Z. Wang, U. Helmersson and P.-O. Käll, (2002) Thin Solid Films 405, 50

41. N. Serpone, D. Lawless and R. Khairutdinov, (1995) J. Phys. Chem. 99, 16646

42. S. Monticone, R. Tufeu, A. V. Kanaev, E. Scolan and C. Sanchez, (2000) Appl. Surf. Sci. 162-163, 565 
43. D. D. D. Ma, C. S. Lee, F. C. K. Au, S. Y. Tong and S. T.Lee, (2003) Science 299, 1874

44. Y. Cui and C. M. Lieber. (2001) Science 291, 851

45. A. J. Lu, R. Q. Zhang and S. T. Lee, (2008) Nanotecnology 19, 1.

46. A. Iacomino, G. Cantele, D. Ninno, I: Marri and S. Ossicini, (2008) Phys. Rev. B 78, 07405; D. N. Tafen and J. P. Lewis, (2009) Phys. Rev. B 80, 014104

47. F. De Angelis, S. Fantacci and A. Selloni, (2008) Nanotechnology 19, 424002

48. R. Wang, K. Hashimoto, A. Fujishima, M. Chikuni, E. Kojima, A. Kitamura, M. Shimohigoshi and T. Watanabe, (1997) Nature 388, 431

49. T. Shibata, N. Sakai, K. Fukuda, Y. Ebina and T. Sasaki (2009) Mat. Sci. and Eng. B 161, 12

50. M. Lazzeri, A. Vittadini, A. Selloni, (2001) Phys. Rew. B 63, 155409

51. H. Kamisaka, K. Yamashita, (2007) Surf. Sci. 601, 4824 


\section{TABLES}

\section{Table I}

Structural, morphological and compositional parameters determined by GIXRD, XSR and XDS measurements on the samples prepared by sol (Sol-1) and polymer sol (Sol-2) deposited on different substrates ( $\mathrm{Si}(100)$ wafer, silica and glass).

\begin{tabular}{|c|c|c|c|c|c|c|}
\hline $\begin{array}{c}\text { precursor } \\
\text { solutions }\end{array}$ & sample & substrate & $\begin{array}{c}\text { mean crystalline } \\
\text { domain size } \\
\langle\mathrm{D}\rangle(\mathbf{n m})\end{array}$ & $\begin{array}{c}\text { film } \\
\text { thickness } \\
\Lambda(\mathbf{n m}) \\
\end{array}$ & $\begin{array}{c}\text { surface } \\
\text { roughness } \\
\sigma_{\mathrm{rsm}}(\mathbf{n m}) \\
\end{array}$ & $\begin{array}{l}\text { mass density } \\
\qquad\left(\mathrm{g} / \mathrm{cm}^{3}\right)\end{array}$ \\
\hline \multirow{3}{*}{ Sol-1 } & A1 & $\mathrm{Si}(100)$ & $14 \pm 1$ & $62 \pm 0.5$ & $0.95 \pm 0.03$ & $3.83(4.05)$ \\
\hline & B1 & silica & $12 \pm 1$ & $64 \pm 0.5$ & $1.00 \pm 0.05$ & $3.56(4.05)$ \\
\hline & C1 & glass & $11 \pm 1$ & - & $2.50 \pm 0.05$ & $3.17(4)$ \\
\hline \multirow{3}{*}{ Sol-2 } & $\mathrm{A} 2$ & $\operatorname{Si}(100)$ & 3.3 & $90 \pm 0.5$ & $1.25 \pm 0.02$ & 3.00 \\
\hline & B2 & silica & 4.6 & $93 \pm 0.5$ & $1.30 \pm 0.03$ & 2.85 \\
\hline & C2 & glass & - & $96 \pm 0.5$ & $1.40 \pm 0.03$ & 3.10 \\
\hline
\end{tabular}

\section{Table 2}

The mean particle diameter $G$ and mean porosity diameter $\left\langle D_{P}\right\rangle$ as measured on the digitalized images of the $\mathrm{TiO}_{2}$ films, and the measured contact angle $\vartheta$ of the $\mathrm{TiO}_{2}$ films. For comparison, also the contact angles of the uncovered substrates are given.

\begin{tabular}{|c|c|c|c|c|c|c|c|}
\hline \multirow{2}{*}{ sample } & \multirow{2}{*}{ substrate } & \multirow{2}{*}{$G(\mathrm{~nm})$} & \multirow{2}{*}{$\begin{array}{c}\text { standard } \\
\text { deviation of } G \\
(\mathrm{~nm})\end{array}$} & \multirow{2}{*}{$\begin{array}{c}\left\langle D_{P}>\right. \\
(\mathbf{n m})\end{array}$} & \multirow{2}{*}{$\begin{array}{c}\text { standard } \\
\text { deviation of } D_{P} \\
(\mathrm{~nm})\end{array}$} & \multicolumn{2}{|c|}{ contact angle $\vartheta\left(^{\circ}\right)$} \\
\hline & & & & & & film & substrate \\
\hline A1 & (100)-Si & 11 & \pm 4 & 2 & \pm 1 & 30 & 56 \\
\hline B1 & fused silica & 11 & \pm 4 & 2 & \pm 1 & 29 & 5 \\
\hline C1 & glass & 11 & \pm 5 & 4 & \pm 2 & 55 & 11 \\
\hline A2 & (100)-Si & 16 & \pm 8 & 7 & \pm 3 & 6 & 56 \\
\hline B2 & fused silica & 16 & \pm 8 & 7 & \pm 3 & 7 & 5 \\
\hline $\mathrm{C} 2$ & glass & 22 & \pm 10 & 17 & \pm 6 & 5 & 11 \\
\hline
\end{tabular}




\section{FIGURES CAPTIONS}

\section{Figure 1}

Experimental GIXRD scans of $\mathrm{TiO}_{2}$ films $\mathrm{A} 1, \mathrm{~B} 1$ and $\mathrm{C} 2$ grown on $\mathrm{Si}(\mathrm{a})$, silica (b) and soda lime glass (c) substrates, respectively.

\section{Figure 2}

Experimental GIXRD scans of $\mathrm{TiO}_{2}$ films A2, B2 and C2 grown on Si (a), silica (b) and soda lime glass (c) substrates, respectively.

\section{Figure 3}

Experimental XSR and XDS patterns recorded on sample A2. The Kiessig interference fringes in the XSR and the Yoneda peaks in the XDS patterns (recorded at different $2 \theta$ detector positions: $0.7^{\circ}, 1.0^{\circ}$ and $1.5^{\circ}$ ) are well observed.

\section{Figure 4}

Experimental (black dots) and simulated (solid line; red line, online) XSR patterns of sample A2. The inset shows an enlarged part of the pattern with the well resolved Kiessig interference fringes.

\section{Figure 5}

SEM images acquired on the surface of $\mathrm{TiO}_{2}$ films grown from Sol-1 on silicon (left) and glass (right) substrates, respectively. 


\section{Figure 6}

SEM images acquired on the surface of $\mathrm{TiO}_{2}$ films grown from Sol-2 on silicon (left) and glass (right) substrates, respectively.

\section{Figure 7}

Refractive index curves versus wavelengths of the $\mathrm{TiO}_{2}$ thin films obtained by using Sol-1 and Sol-2 on silica (B1, B2) and soda lime (C1, C2) substrates.

\section{Figure 8}

Dispersion of $(\alpha h v)^{1 / 2}$ versus photon energy $(h v)$ (indirect transition) of the titania coatings prepared by Sol-1 (a) and Sol-2 (b), respectively.

\section{Figure 9}

Dispersion of $(\alpha h v)^{2}$ versus photon energy (hv) (direct transition) and graphical estimation of the gap energy of the titania coatings prepared by Sol-1 (a) and Sol-2 (b), respectively. 


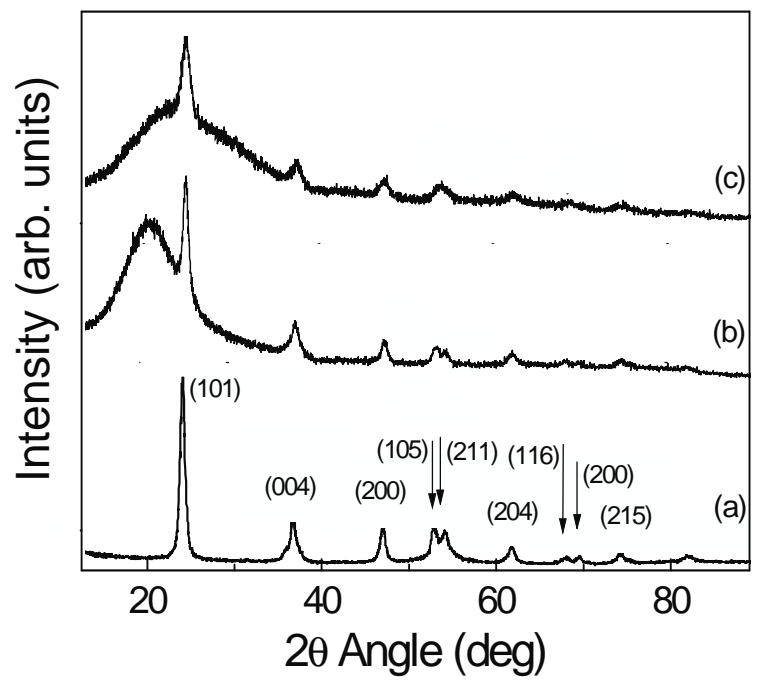

Figure 1 


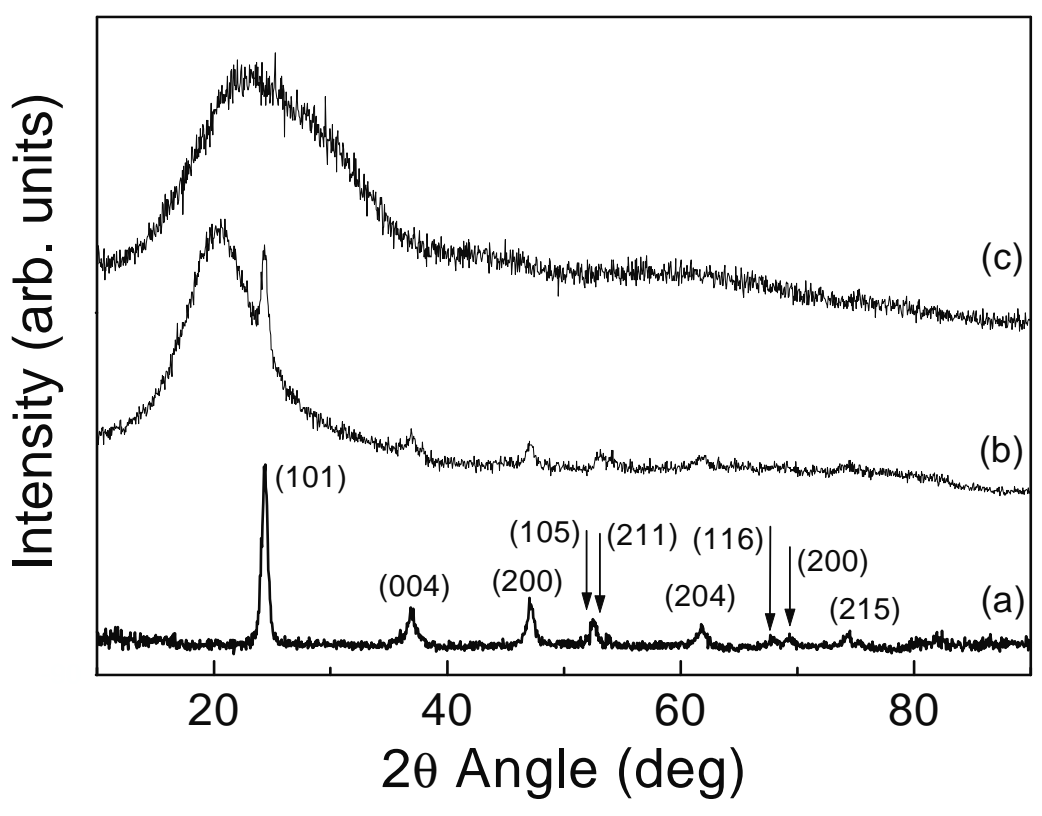

Figure 2 


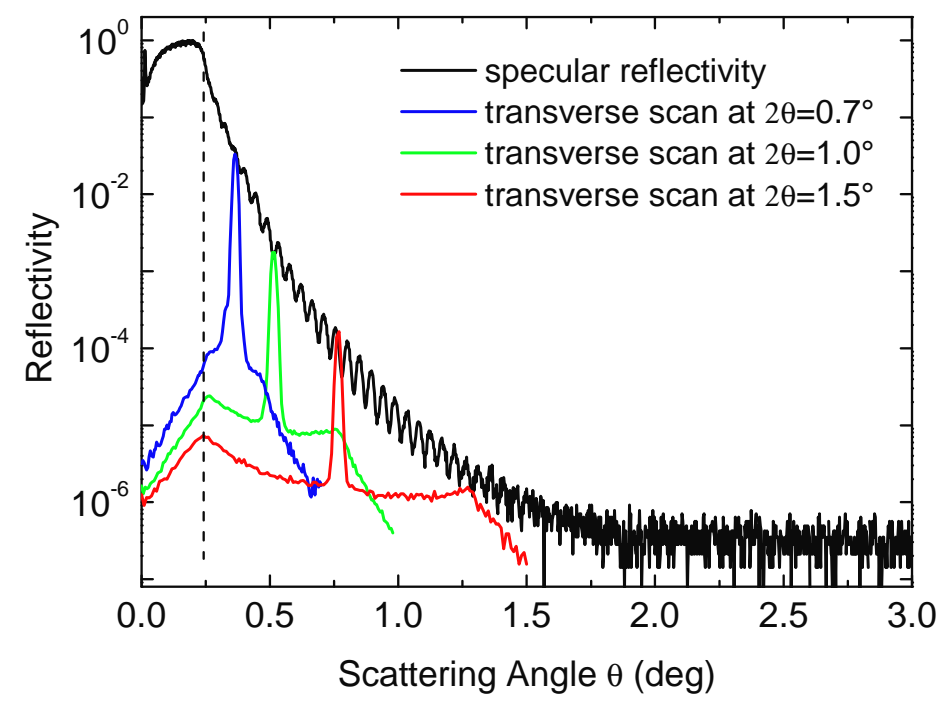

Figure 3 


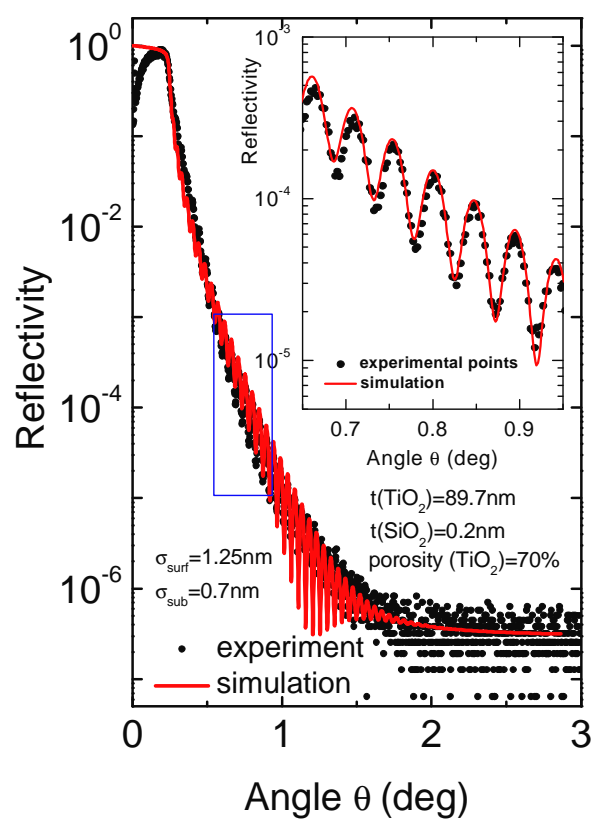

Figure 4 

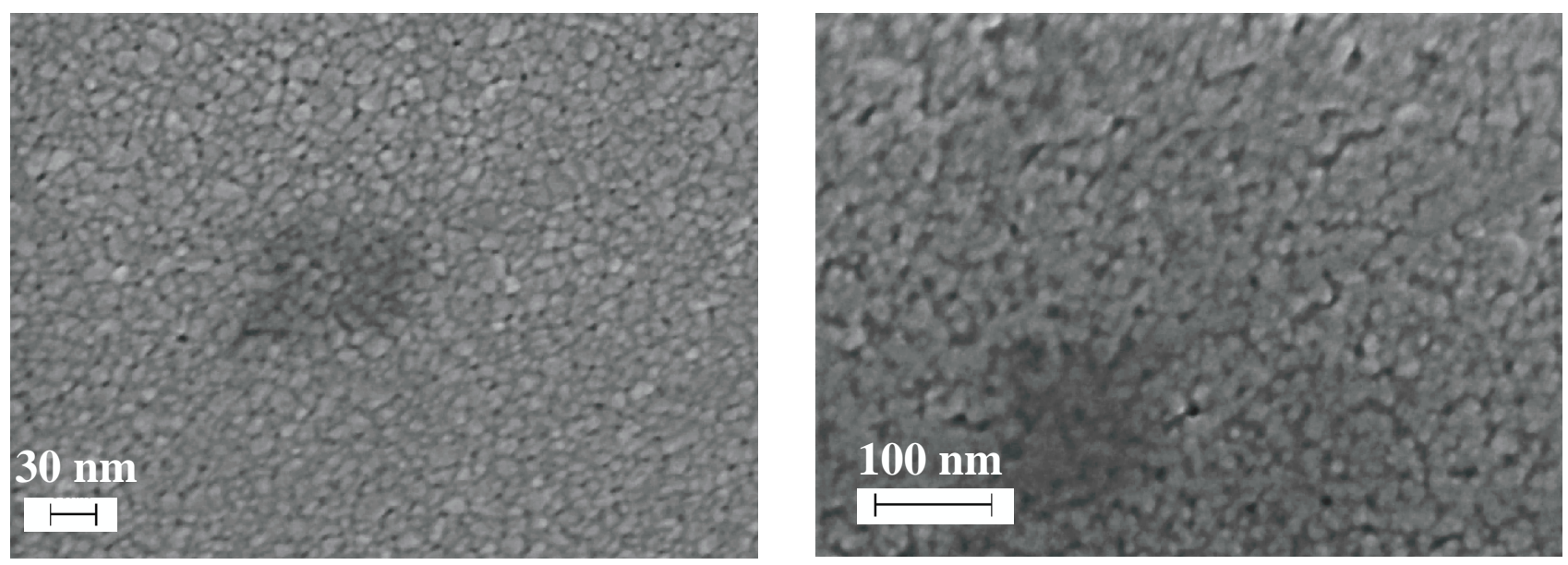

Figure 5 

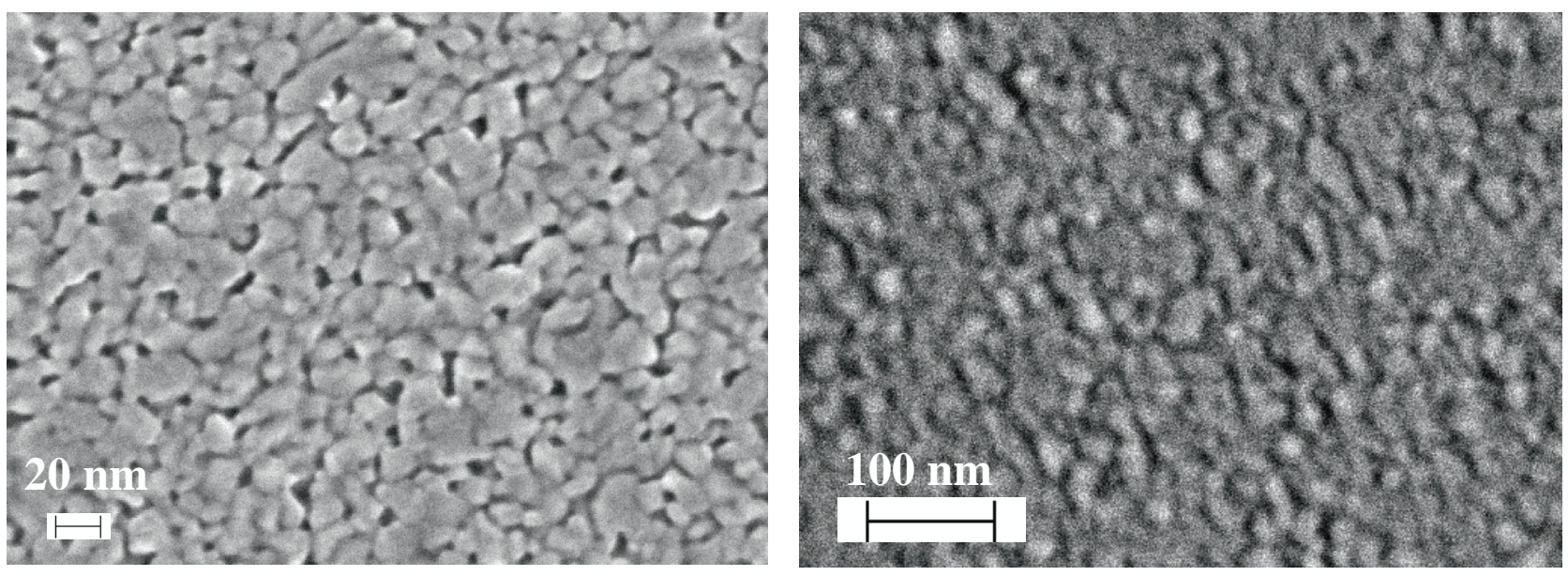

Figure 6 


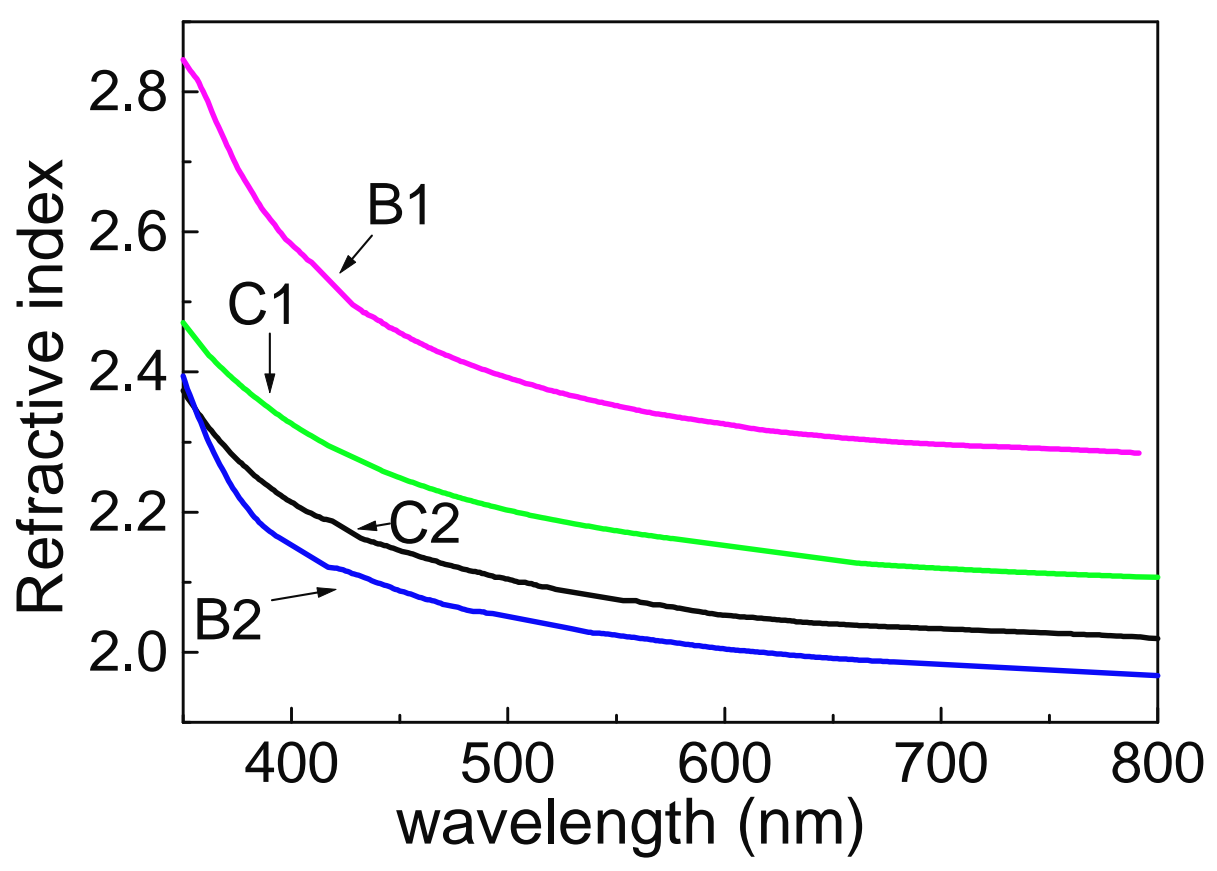

Figure 7 


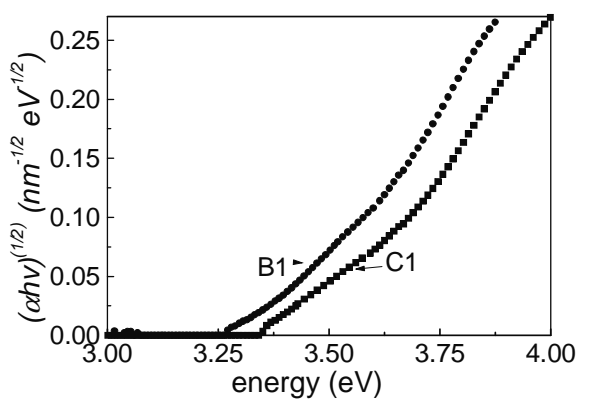

(a)

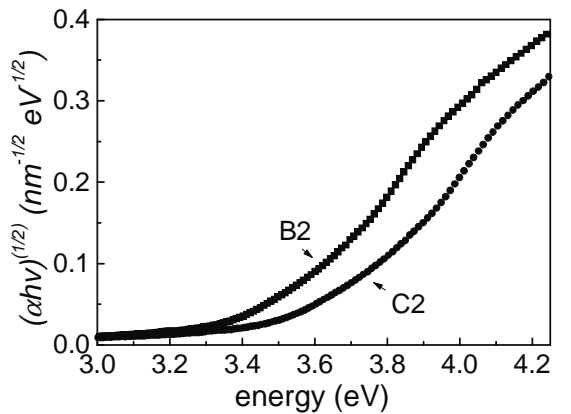

(b)

Figure 8 


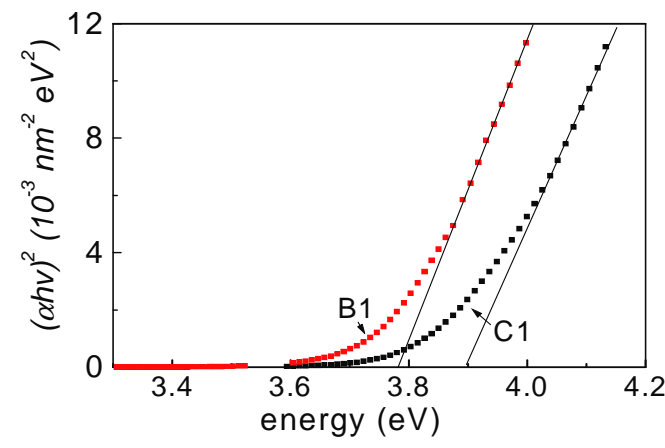

(a)

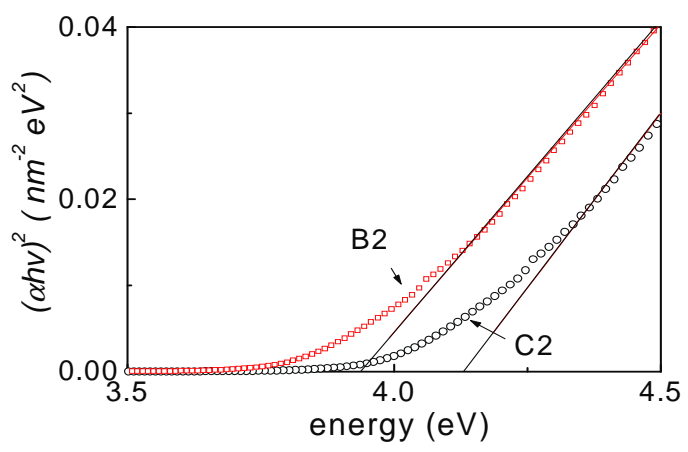

(b)

Figure 9 
